\title{
High Temperature Friction and Wear Behavior of Cold-Sprayed Ti6Al4V and Ti6Al4V-TiC Composite Coatings
}

\author{
Venkata Naga Vamsi Munagala ${ }^{1}$, Tyler B. Torgerson ${ }^{2}$, Thomas. W. Scharf ${ }^{2}$, and Richard. R. \\ Chromik $^{1}$ \\ ${ }^{1}$ Department of Mining and Materials Engineering, McGill University, Montreal, QC H3A 0C5, \\ Canada \\ ${ }^{2}$ Department of Materials Science and Engineering, University of North Texas, Denton, TX \\ 76203, USA
}

\begin{abstract}
The poor wear resistance of titanium and its alloys often results in galling and high wear rates. One method to improve their wear resistance is by hard secondary phase reinforcement to create a metal matrix composite, which can be utilized in the bulk or as a coating. In the present study, Ti6Al4V coatings and Ti6A14V-TiC metal matrix composite coatings were deposited on mild steel substrates using cold spray process and their dry sliding wear behaviour was studied over a static temperature range of $25-575^{\circ} \mathrm{C}$. Tests were performed using a unidirectional ball-on-disc tribometer with WC-Co sphere as the counterface at a load of $2.5 \mathrm{~N}$ and sliding velocity of 2.1 $\mathrm{cm} . \mathrm{s}^{-1}$. Wear rate and coefficient of friction $(\mathrm{CoF})$ decreased with an increase in temperature and composite coatings exhibited higher wear resistance at all temperatures. Below $200^{\circ} \mathrm{C}$, abrasive wear characterized by ploughing by wear debris resulted in high wear of Ti6Al4V coatings, whereas formation of tribolayers led to lower wear of composite coatings. At elevated temperatures $\left(>200^{\circ} \mathrm{C}\right)$, oxide glaze layers formed on both coatings were composed of $\mathrm{WO}_{3}, \mathrm{TiO}_{2}$ and $\mathrm{CoWO}_{4}$. Electron channel contrast imaging of the wear track cross-sections showed no splat debonding, less extent of recrystallization and larger grain sizes (at $575^{\circ} \mathrm{C}$ ) in composite coatings compared to Ti6Al4V.
\end{abstract}

Keywords: Cold spray, Metal matrix composites, Sliding wear, Ti6A14V, Tribo-oxides 


\section{Introduction}

During wear, metal matrix composite (MMC) coatings form tribolayers that are often beneficial and improve tribological properties in comparison to a pure metal coating of the same material as the matrix [1-6]. Tribolayers form due to the agglomeration of third bodies that are generated from one or both of the mating surfaces (first bodies) during wear [7-10]. The presence of tribolayers, which often have different properties than the first bodies, alter the contact conditions and tribology of the system [3,7]. Alidokht et al. and Torgerson et al. studied the sliding wear of cold sprayed Ni and Ni-WC composite coatings and found that the reinforcement of WC in Ni matrix facilitated the formation of tribolayers during dry sliding wear which improved the wear resistance compared to pure Ni coatings [6,8]. To enhance the tribological properties of Ti6Al4V, Zhang et al. artificially sprinkled $\mathrm{TiO}_{2}$ and $\mathrm{Fe}_{2} \mathrm{O}_{3}$ nanoparticles during the sliding wear tests to accelerate the formation of tribolayers [11]. They concluded that a minimum mixture of $\mathrm{TiO}_{2}-50 \mathrm{vol} . \% \mathrm{Fe}_{2} \mathrm{O}_{3}$ was required to form tribolayers that increase the load bearing capacity and thus reduce the wear rate. Studies performed by $\mathrm{Du}$ et al. on wear behavior of $\mathrm{NiCr} / \mathrm{Cr}_{3} \mathrm{C}_{2}-\mathrm{NiCr} / \mathrm{hBN}$ coatings show that presence of $\mathrm{hBN}$ improved the wear resistance and reduced the $\mathrm{CoF}$ compared to $\mathrm{NiCr} / \mathrm{Cr}_{3} \mathrm{C}_{2}$ [12]. They reported that formation of a surface layer with embedded hBN particles, reduced the adhesion between the mating surfaces and improved tribological properties. Based on the above studies, the hard phase or solid lubricant changed the kinetics of tribolayer formation and also imparted better properties and wear resistance.

The nature of tribolayers formed on metals and MMCs will change with temperature. Other than mechanical mixing, tribo-oxidation with the atmosphere and tribochemical reactions between the two first bodies are the main mechanisms for tribolayer formation. At elevated temperatures, tribolayers are often referred as glaze layers since they are compacted layers of tribo-oxides comprising of third bodies from either one or both the mating surfaces. In terms of Ti alloys, Cui et al. studied the sliding wear behavior of Ti6Al4V coatings in a temperature and load range of $20-400^{\circ} \mathrm{C}$ and $50-250 \mathrm{~N}$, respectively [13]. They found that an increase in temperature up to $200^{\circ} \mathrm{C}$

increased the wear rate with abrasive and adhesive wear resulting in severe wear. Beyond $200^{\circ} \mathrm{C}$, the wear rate decreased due to the formation of protective tribolayers resulting in mild wear. Wang et al. performed sliding wear test on $\mathrm{Ti}$ alloys within a range of $25-600^{\circ} \mathrm{C}$ with steel as counterface [14]. They reported a transition in wear mechanisms between $300-400^{\circ} \mathrm{C}$ from predominantly 
abrasive to oxidative wear, which significantly decreased the wear rate. The change in wear mechanism and improvement in wear resistance was attributed to the continuous formation of hard tribolayers (or oxide glaze layers) comprising of $\mathrm{Ti}$ and Fe-based oxides. In addition, similar results of improvement in wear resistance of a Ti alloy sliding against steel counterface due to the formation of tribolayer beyond $200^{\circ} \mathrm{C}$ was reported by Chen et al. [15] The studies mentioned above illustrate that below $\sim 300^{\circ} \mathrm{C}$, Ti alloys exhibit severe abrasive wear due to the inability of their tribo-oxides to coalesce and form protective tribolayers, while the tribolayer formation occurs only beyond $\sim 300^{\circ} \mathrm{C}$.

Thus, Ti alloys show different friction and wear mechanisms with changes in temperature due to the formation of tribolayers of different chemical compositions based on the elements present at the tribo-pair interface. Furthermore, the sliding wear of Ti6Al4V based MMC coatings at elevated temperatures is not extensively studied in the literature. The aim of the present study is to understand the tribological behavior of cold sprayed Ti6Al4V and Ti6Al4V-TiC MMC coatings over a temperature range of $25-575^{\circ} \mathrm{C}$. The effects of temperature and $\mathrm{TiC}$ reinforcement in modifying the friction and wear mechanisms was investigated in detail. Electron channel contrast imaging (ECCI) was done on the wear track cross-sections to characterize the third bodies and subsurface microstructures. In addition, nanoindentation was performed on the third bodies to determine their hardness. 


\section{Experimental procedure}

\subsection{Cold spray of coatings and characterization}

Irregular Ti6A14V (Cristal Metals, USA) and spherical TiC (Tekna, Canada) powders of size range: $0-45 \mu \mathrm{m}$ and $15-45 \mu \mathrm{m}$ were cold sprayed to deposit Ti6Al4V and Ti6Al4V-TiC MMC coatings. The size distribution, average particle diameter and microstructure of the two feedstock powders were reported in previous publications $[9,16]$. Coatings were deposited on to mild steel plates (substrate) of dimensions $75 \times 75 \times 3 \mathrm{~mm}^{3}$ using a high pressure cold spray system PCS 800 (Plasma Giken, Japan). Prior to deposition the substrates were de-greased and grit blasted using alumina to enhance the coating-substrate bonding. Nitrogen $\left(\mathrm{N}_{2}\right)$ was used as propellant gas with pressure and temperature fixed at $4 \mathrm{MPa}$ and $800^{\circ} \mathrm{C}$ for all the coatings. The standoff distance between the nozzle and substrate was $40 \mathrm{~mm}$ and the gun traverse speed was $0.2 \mathrm{~m} . \mathrm{s}^{-1}$. The CS system used was equipped with a dual feeding system in which Ti6Al4V and TiC powders were fed into two separate hoppers. During the deposition of Ti6Al4V coatings, Ti6Al4V powder was fed through the nozzle whereas for the deposition of composite coatings both hoppers (i.e. dual feeding system) were activated. The feed rate of the hoppers was adjusted separately to get the required initial metal-ceramic mixture at the inlet of the nozzle.

Deposition efficiency (DE) of the coatings was determined using Eq. 1-3. After CS deposition, coatings were cut perpendicular to the gun traverse direction, cold mounted and polished down till $0.05 \mu \mathrm{m}$ using colloidal silica suspension. The polished samples were characterized using a scanning electron microscope (SEM) SU3500 (Hitachi, Japan) equipped with a back scattered electron (BSE) detector. BSE images were taken at different locations across the sample crosssection and were uploaded into ImageJ software and the pixels associated with their respective contrast was calculated to determine the porosity and ceramic retention percentages. At least 15 images taken at various locations were analysed to calculate the final average values in each case.

$D E(\%)=\frac{\text { Weight of the powder deposited }\left(W_{d}\right)}{\text { Weight of the powder sprayed }\left(W_{S}\right)}$

$W_{d}=$ Weight of the sample (after coating) - Weight of the substrate

$W_{s}=\frac{\text { Powder feedrate } \times \text { Distance travelled by the gun on the sample }}{\text { Gun traverse speed }}$ 
Microhardness tests were performed on the polished coating surface at random locations using a Vickers microhardness tester (Buehler, USA) at $5 \mathrm{~kg}$ load and $15 \mathrm{~s}$ holding time. This indentation load was chosen to have the indenter interact with the reinforced carbide particles along with the matrix. An average of 10 indents was done to calculate the average hardness.

\subsection{Sliding wear tests}

Dry sliding wear tests on the coatings were performed using a unidirectional ball-on disc tribometer Falex ISC-450 (Falex Corporation, USA). The tribometer was equipped with a heating stage (on which the sample was mounted), a temperature controller (Honeywell, USA) and a thermocouple. The thermocouple, temperature controller and the heating stage were connected through a feedback loop wherein the temperature controller collects the data through the thermocouple and activates or de-activates the heating coil placed under the heating stage to maintain the desired static test temperature. WC-Co balls of diameter $6.35 \mathrm{~mm}$ were used as counterface for all the tests. The sliding wear tests were conducted in ambient air ( 40\% RH) under a normal load of $2.5 \mathrm{~N}$ ( $\sim 0.8 \mathrm{GPa}$ initial maximum Hertzian contact stress), which was chosen to be below the $\sim 0.9 \mathrm{GPa}$ yield strength of Ti6Al4V alloy. The sliding speed was fixed at $2.1 \mathrm{~cm} . \mathrm{s}^{-1}$ and all the tests were run for a total sliding distance of $200 \mathrm{~m}$ to observe the steady-state friction behavior. At least two sliding tests were performed on each coating at every temperature up to $400^{\circ} \mathrm{C}$ while for test at $575^{\circ} \mathrm{C}$ only one test was done due to constraints from the experimental setup. Coatings used for the wear tests were polished using 400 to 1200 grit SiC abrasive paper, subsequently using $9 \mu \mathrm{m}, 3 \mu \mathrm{m}, 1 \mu \mathrm{m}$ diamond suspension solution and finally using $0.05 \mu \mathrm{m}$ colloidal silica suspension. Sliding wear tests were performed at $25^{\circ} \mathrm{C}, 200^{\circ} \mathrm{C}, 400^{\circ} \mathrm{C}$ and $575^{\circ} \mathrm{C}$ static test temperatures for both Ti6Al4V and Ti6Al4V-TiC composite coatings. The above temperature range was choosen since $\mathrm{Ti}$ and its alloys are widely used in aerospace applications where they are subjected to elevated temperatures up to $\sim 600^{\circ} \mathrm{C}$ [14]. The coefficient of friction $(\mathrm{CoF})$ for the entire test duration was recorded using the software supplied by the manufacturer. Generally, in a sliding wear test there is a running-in period characterized by either sharp rise or fall in $\mathrm{CoF}$ followed by a steady state regime where the CoF converges approximately to a stable value. In the present study, the average $\mathrm{CoF}$ was calculated by averaging the $\mathrm{CoF}$ after it had reached steady state. The steady state regime was chosen based on the criteria that the CoF did not abruptly rise or fall beyond a value of \pm 0.05 for the subsequent sliding distance till the end of the 
test. For all the coatings the steady state was found to be lasting for at least $150 \mathrm{~m}$ after the initial running-in period. To calculate the wear rate, wear tracks were analyzed under a non-contact optical profilometer (Zygo Corporation, USA) and profiles were generated across the wear tracks. A minimum of 35 profiles were used to calculate the wear area (by integrating the profiles above and below the surface), that was subsequently averaged and multiplied with the total track length to determine the final wear volume $\left(\mathrm{mm}^{3}\right)$. The wear volume was normalized with load $(\mathrm{N})$ and total sliding distance $(\mathrm{m})$ to calculate the wear rate $\left(\mathrm{mm}^{3} \cdot \mathrm{N}^{-1} \cdot \mathrm{m}^{-1}\right)$. Profilometry was performed on the worn counterface using a non-contact optical profilometer to calculate the wear volume. The worn counterface was fitted with a sphere of same radius and was flattened to determine the volume below the unworn region (reference surface). The volume below the unworn region was considered as wear volume.

The worn surface and counterface after the wear tests were characterized using an SEM SU3500 equipped with an energy-dispersive X-ray spectroscope (EDS) and BSE detectors. Raman analysis was also performed on the wear tracks and counterface using an inVia Raman spectrometer (Renishaw, UK) with $\mathrm{Ar}^{+}$laser source of $\lambda=514.5 \mathrm{~nm}$. To characterize the subsurface microstructure, ECCI was performed on the wear track cross-sections using a FE-SEM SU8230 (Hitachi, Japan) equipped with a BSE detector. Nanoindentation was performed on the wear track cross-sections using a Triboindentor (Hysitron Corporation, USA) at a peak load of $5 \mathrm{mN}$ using a Berkovich tip. The hardness of the tribolayer and the subsurface was determined from the loaddisplacement curves using Oliver and Pharr method and each hardness value represents an average of 5 to 10 indents [17]. Indentation was done in a grid pattern on the wear track cross-sections from the unworn coating up to the worn surface. Subsequently, the residual indent images were matched with the corresponding pre-indent images and load-displacement curves to obtain the required features of interest.

\section{Results}

\subsection{Cold spray, characterization and properties of the coatings}

Ti6Al4V and Ti6A14V-TiC coatings were cold sprayed and the DE, porosity, ceramic retention, hardness and thickness values are summarized in Table 1. From Table 1, the DE of composite coating was significantly less than Ti6Al4V coatings mainly due to the non-bonding nature of the ceramic particles. Fig. 1a and 1b show the BSE images of the cross-section of the Ti6Al4V and 
Ti6A14V-TiC composite coatings. In the BSE images of the composite coatings (Fig. 1b), the grey contrast of the spherical and fragmented particles corresponds to the ceramic particles whereas the dark spots correspond to porosity (shown by white arrows in Fig. 1b). BSE images reveal that the Ti6Al4V coatings were dense with negligible porosity whereas the composite coatings showed evidence of some porosity due to the fragmentation of ceramic particles. Ceramic retention in the composite coatings was found to be lower compared to the initial feedstock. Initially, a mixture of $50 \mathrm{vol} . \%$ of metal and ceramic were cold sprayed and only $23 \mathrm{vol} . \%$ was retained in the coatings that correspond to $46 \%$ of ceramic in the initial feedstock. The hardness of the composite coatings was higher compared to pure Ti6Al4V coatings (Table 1) due to the presence of ceramic particles that increase the load-bearing capacity.

Table 1: Coating characteristics

\begin{tabular}{ccccccc}
\hline Coating & $\begin{array}{c}\text { Deposition } \\
\text { efficiency } \\
(\%)\end{array}$ & $\begin{array}{c}\text { Porosity } \\
\mathbf{( \% )}\end{array}$ & $\begin{array}{c}\text { Ceramic in } \\
\text { the initial } \\
\text { feedstock } \\
\text { (vol.\%) }\end{array}$ & $\begin{array}{c}\text { Ceramic } \\
\text { retention } \\
\text { (vol.\%) }\end{array}$ & $\begin{array}{c}\text { Hardness } \\
\text { (HV) }\end{array}$ & $\begin{array}{c}\text { Thickness } \\
\text { (mm) }\end{array}$ \\
\hline Ti6Al4V & 92 & $0.3 \pm 0.1$ & --- & --- & $191 \pm 12$ & $1.7 \pm 0.04$ \\
Ti6Al4V-TiC & 42 & $1.0 \pm 0.4$ & 50 & 23 & $274 \pm 19$ & $1.0 \pm 0.06$ \\
\hline
\end{tabular}
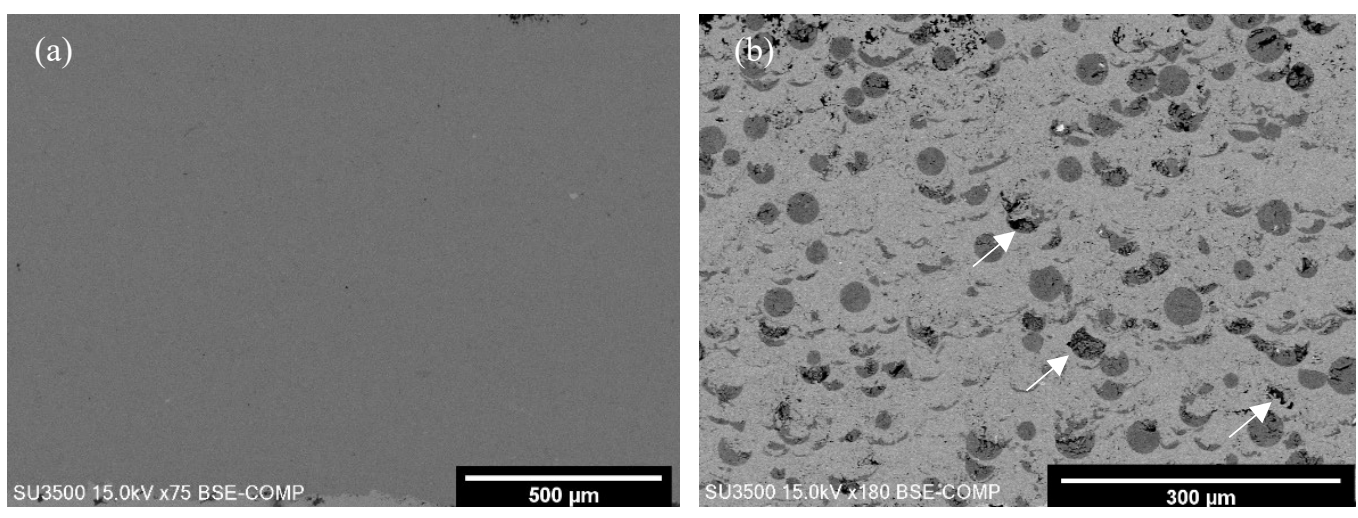

Fig. 1: SEM images of (a) Ti6Al4V (b) Ti6A4V-TiC composite coating. White arrows indicate porosity due to ceramic fragmentation.

\subsection{Sliding wear of Ti6Al4V and Ti6Al4V-TiC coatings}

\subsubsection{Friction and wear behavior of the coatings}

Figure 2a shows the wear rates of Ti6Al4V and Ti6Al4V-TiC composite coatings at different test temperatures. There was a trend of decreasing wear rate with increased temperature in both the 
coatings. At all test temperatures, the composite coating had a lower wear rate compared to Ti6Al4V coating (see Fig. 2a). For example, composite coating exhibited approximately 7 times lower wear rate compared to Ti6Al4V coating at $25^{\circ} \mathrm{C}$ (room temperature). At higher temperatures $\left(400^{\circ} \mathrm{C}\right.$ and $\left.575^{\circ} \mathrm{C}\right)$, composite coating showed negative wear rate (i.e. material gain on the wear track was recorded due to the transfer from the counterface). For the Ti6Al4V coatings, there was some amount of wear that occurred irrespective of the temperature. However, the difference in the wear rates between $\mathrm{Ti} 6 \mathrm{Al} 14 \mathrm{~V}$ and the Ti6Al4V-TiC composite coating became less as the test temperature increased (see Fig. 2a).

Figure $2 \mathrm{~b}$ shows the average $\mathrm{CoF}$ of the Ti6Al4V and Ti6Al4V-TiC composite coatings. The average CoF was between $0.25-0.45$ for both coatings at all test temperatures. To check the hypothesis that the average CoF of Ti6Al4V and composite coatings at all the temperatures was statistically different, an independent samples t-test (i.e. student's t-test) was performed with the probability (p) value to accept null hypothesis (i.e. there is no significant difference between the means) greater than 0.05 . $\mathrm{T}$ Test results showed that the average CoF was different both in pure Ti6Al4V and composite coatings at all temperatures. For the case of Ti6Al4V coatings, the average CoF increased initially and then decreased with temperature, whereas in the composite coatings the average $\mathrm{CoF}$ decreased with an increase in temperature. Above $200^{\circ} \mathrm{C}$, the Ti6Al4V-TiC coating exhibits lower CoF than Ti6Al4V coating.

(a)

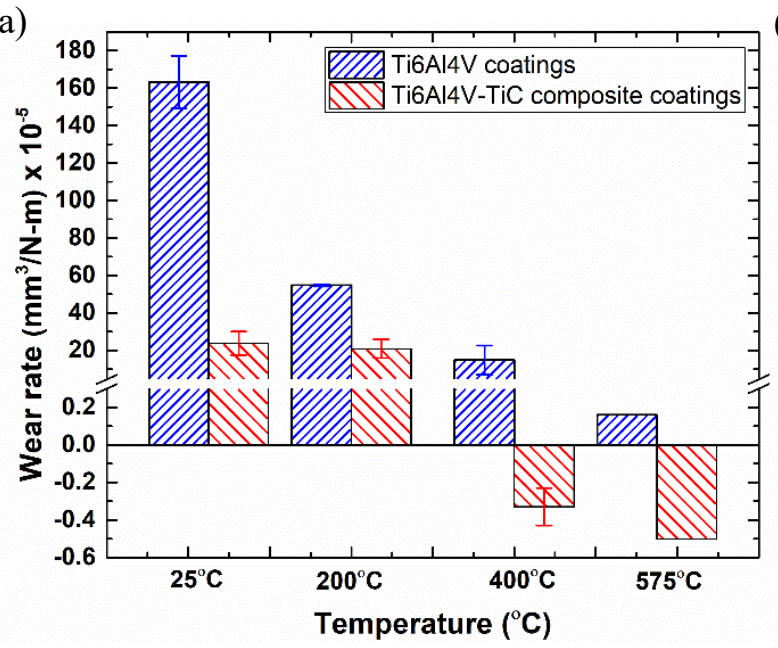

(b)

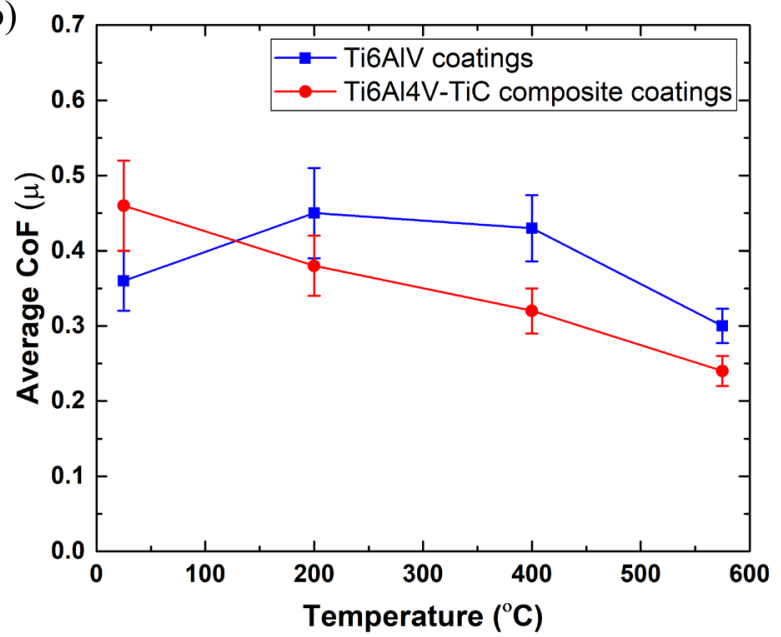

Fig. 2: (a) Wear rate (b) average $\mathrm{CoF}$ of the coatings. 


\subsubsection{Wear track morphology}

The worn surface morphology of the coatings after sliding wear tests at different temperatures are shown in Fig. 3 and 4. Worn surface of Ti6Al4V coating at $25^{\circ} \mathrm{C}$ showed abrasive wear with grooves aligned in the sliding direction (Fig. 3a). These grooves were formed due to the scoring action caused by the entrapped wear debris and the counterface during sliding. Additionally, wear debris were found to be displaced on either side of the track along with few patches inside the track as seen in Fig. 3a. A similar abrasive wear mechanism was found at $200^{\circ} \mathrm{C}$ (Fig. 3c). However, at $200^{\circ} \mathrm{C}$ the grooves were found to be deeper (see Fig. 3c) compared to $25^{\circ} \mathrm{C}$. At $400^{\circ} \mathrm{C}$ and $575^{\circ} \mathrm{C}$, the wear tracks are characterized by different features compared to $25^{\circ} \mathrm{C}$ and $200^{\circ} \mathrm{C}$. These wear tracks are covered with a compact tribolayer (or glaze layer) indicating a change in wear mechanisms (see Fig. 3e and g). However, apart from tribolayers, abrasive grooves in the sliding direction were still visible on the wear track at $400^{\circ} \mathrm{C}$, but to a lesser extent as compared to $200^{\circ} \mathrm{C}$. Furthermore, a uniform coverage of the wear track with tribolayer was found at $575^{\circ} \mathrm{C}$ (Fig. $3 \mathrm{~g}$ ) with no evidence of abrasive wear.

Figure 4 shows the wear track morphology of the composite coatings at different test temperatures. At $25^{\circ} \mathrm{C}$, tribolayers were found to be covering the entire wear track (see Fig. 4a). Additionally, minor abrasive grooves formed due to ploughing by the wear debris were found on the wear track, which is a characteristic of abrasive wear. Similarly, at $200^{\circ} \mathrm{C}$, tribolayers along with abrasive grooves were found on the wear track, however the area covered by the tribolayer at this temperature was less compared to $25^{\circ} \mathrm{C}$ (Fig. $4 \mathrm{c}$ ). At $400^{\circ} \mathrm{C}$ and $575^{\circ} \mathrm{C}$, the wear track was covered with a tribolayer (or glaze layer) similar to Ti6Al4V coatings (Fig. 4e and 4g). Along with tribolayers, a few shallow wear scars along the direction of sliding were found on the wear track. At $400^{\circ} \mathrm{C}$, the tribolayer was partially covering the wear track (Fig. $4 \mathrm{e}$ ), whereas at $575^{\circ} \mathrm{C}$, the tribolayer was found to be covering the entire wear track (Fig. 4g). 

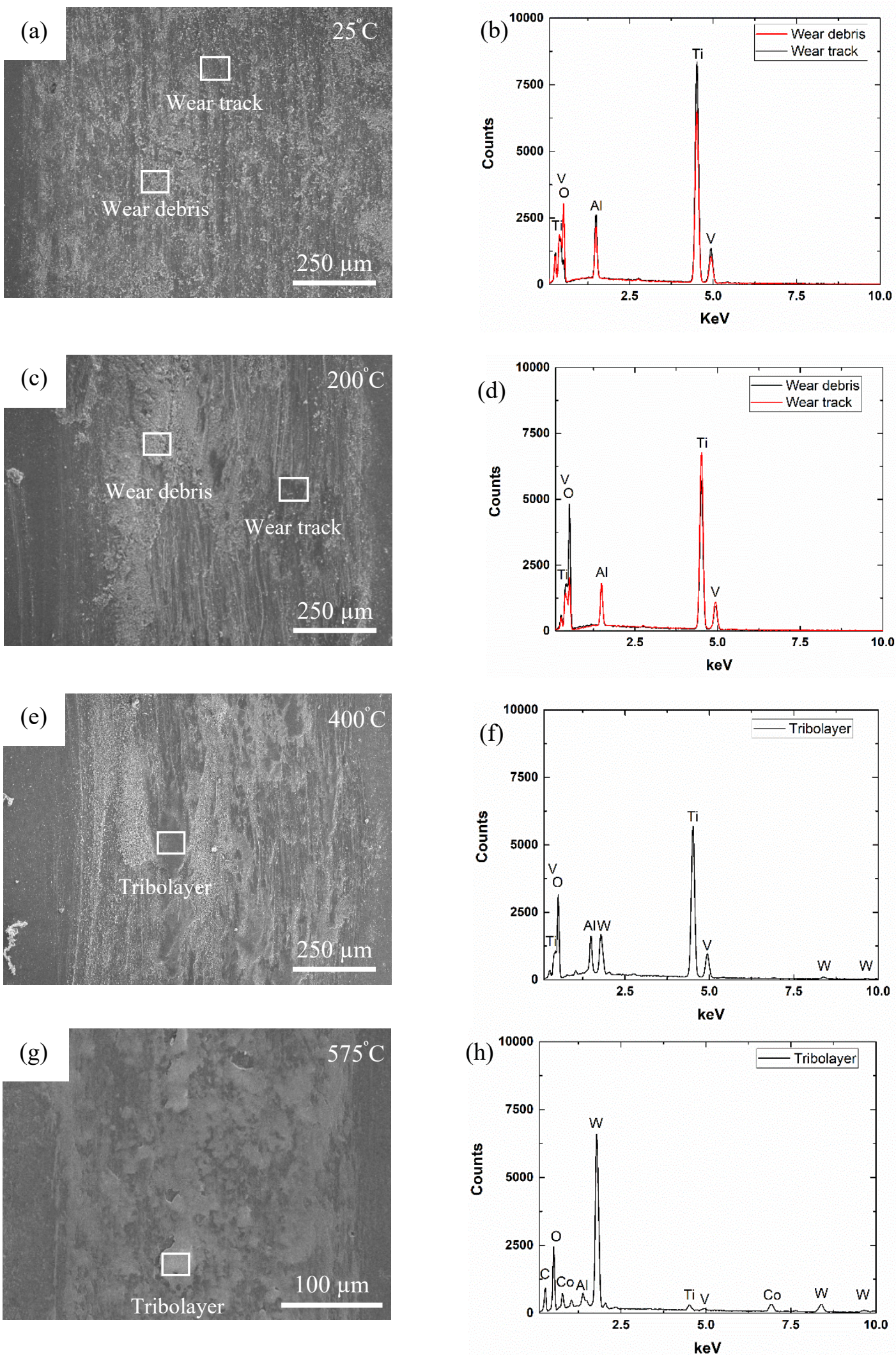

Fig. 3: SEM images of wear track of Ti6Al4V coatings tested at (a) $25^{\circ} \mathrm{C} \mathrm{(c)} 200^{\circ} \mathrm{C}$ (e) $400^{\circ} \mathrm{C}(\mathrm{g}) 575^{\circ} \mathrm{C}$ and (b), (d), (f), (h) EDS spectra taken at respective positions on the wear tracks. 

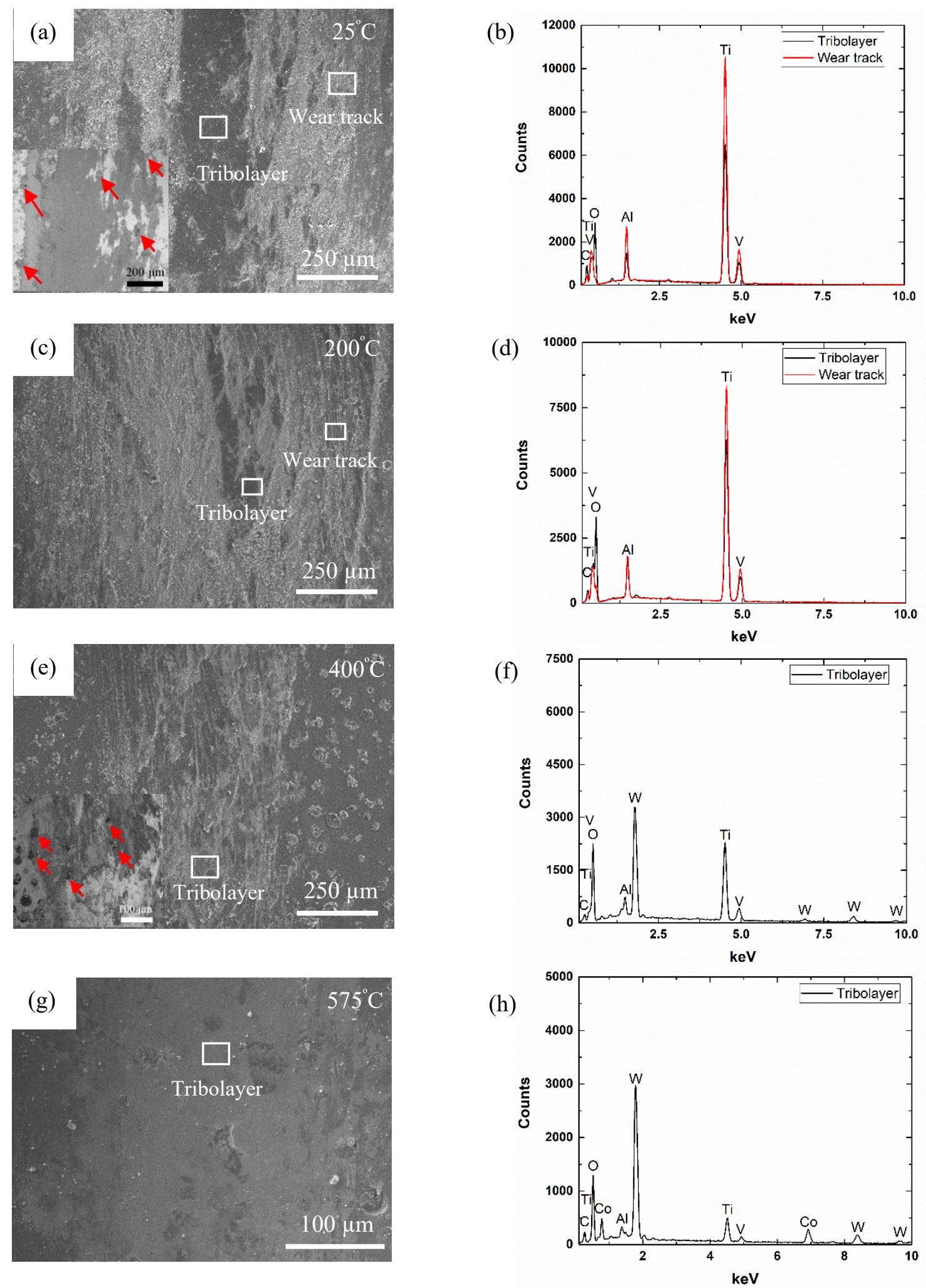

Fig. 4: SEM images of wear track of Ti6Al4V-TiC coatings tested at (a) $25^{\circ} \mathrm{C}$ (c) $200^{\circ} \mathrm{C}$ (e) $400^{\circ} \mathrm{C}(\mathrm{g})$ $575^{\circ} \mathrm{C}$ and (b), (d), (f), (h) EDS spectra taken at respective positions on the wear tracks. Inset images in (a) and (e) show BSE image of tribolayers with arrows showing fragmented TiC particles. 


\subsubsection{Wear track chemical analysis}

EDS analysis on the wear track of Ti6Al4V coating at $25^{\circ} \mathrm{C}$ and $200^{\circ} \mathrm{C}$ revealed the presence of $\mathrm{Ti}, \mathrm{Al}, \mathrm{V}$ and $\mathrm{O}$ both on the wear track as well as on wear debris (Fig. 3b and 3d). However, the amount of oxygen content in the wear debris and wear track increased with an increase in temperature due to greater oxidation. At $400^{\circ} \mathrm{C}, \mathrm{W}$ was also found along with $\mathrm{Ti}, \mathrm{Al}, \mathrm{V}$ and $\mathrm{O}$ in the tribolayers (see Fig. 3f). The W in the tribolayer was due to the transfer of the WC-Co ball material during the wear process. Furthermore, as the test temperature increased to $575^{\circ} \mathrm{C}, \mathrm{W}, \mathrm{C}$ and $\mathrm{Co}$ were also found along with $\mathrm{Ti}, \mathrm{Al}, \mathrm{V}$ and $\mathrm{O}$ on the wear track that was covered with tribolayer (see Fig. 3h).

In contrast, EDS analysis on the wear track of composite coatings showed the presence of different elemental compositions with increasing test temperatures. EDS of the worn surface of the composite coatings at $25^{\circ} \mathrm{C}$ and $200^{\circ} \mathrm{C}$ showed the presence of $\mathrm{Ti}, \mathrm{Al}, \mathrm{V}, \mathrm{O}$ and $\mathrm{C}$ on the tribolayers and wear track (Fig. 4b and 4d). However, the amount of $\mathrm{C}$ and $\mathrm{O}$ detected was higher on the tribolayers as compared to the wear track (see Fig. $4 \mathrm{~b}$ and $4 \mathrm{~d}$ ). At $400^{\circ} \mathrm{C}$ and $575^{\circ} \mathrm{C}$, EDS analysis on the tribolayer also revealed the presence of $\mathrm{W}$, and additionally Co (only at $575^{\circ} \mathrm{C}$ ), due to WCCo ball transfer, along with Ti, Al, V, O and C (Fig. 4f and 4h). Furthermore, C content on the wear track decreased as the temperature increased due to limited exposure of $\mathrm{TiC}$ carbide particles as they were masked by the oxide-rich tribolayers. However, at $575^{\circ} \mathrm{C}$, the higher $\mathrm{C}$ content could be due to the transfer of material from the counterface. Compared to Ti6Al4V coatings, composite coatings showed higher amount of $\mathrm{W}$ at $400^{\circ} \mathrm{C}$ and $\mathrm{Co}$ at $575^{\circ} \mathrm{C}$ correspondingly, indicating more material transfer from the ball.

To identify the tribochemical phases formed, Raman analysis was performed on the wear track and tribolayers at the respective test temperatures and the resultant peaks corresponding to the Raman shift were matched with those reported in the literature [9,18-20]. Raman analysis on the wear debris of the Ti6Al4V coatings tested at $25^{\circ} \mathrm{C}$ and $200^{\circ} \mathrm{C}$ showed characteristic peaks at 143 $\mathrm{cm}^{-1}, 270 \mathrm{~cm}^{-1}, 405 \mathrm{~cm}^{-1}$ and $609 \mathrm{~cm}^{-1}$ corresponding to rutile and anatase phases of $\mathrm{TiO}_{2}$ (Fig. 5a and 5b). However, on the wear track at $25^{\circ} \mathrm{C}$ and $200{ }^{\circ} \mathrm{C}$, no peaks were detected (Fig. 5a and 5b) and was similar to the Raman spectra of as-sprayed coating (Fig. 5a), whereas at $400^{\circ} \mathrm{C}$, peaks corresponding to $\mathrm{TiO}_{2}$ were observed. Tribolayers formed at $400^{\circ} \mathrm{C}$ revealed peaks at $870 \mathrm{~cm}^{-1}$ and 
$1583 \mathrm{~cm}^{-1}$ corresponding to $\mathrm{WO}_{3}$ and $\mathrm{C}$ (Fig. $5 \mathrm{c}$ ) respectively, along with $\mathrm{TiO}_{2}$. At $575^{\circ} \mathrm{C}$, a sharp peak at $885 \mathrm{~cm}^{-1}$ corresponding to $\mathrm{CoWO}_{4}$ (Fig. $5 \mathrm{c}$ ) was observed on the tribolayers in addition to $\mathrm{TiO}_{2}$ and $\mathrm{WO}_{3}$.
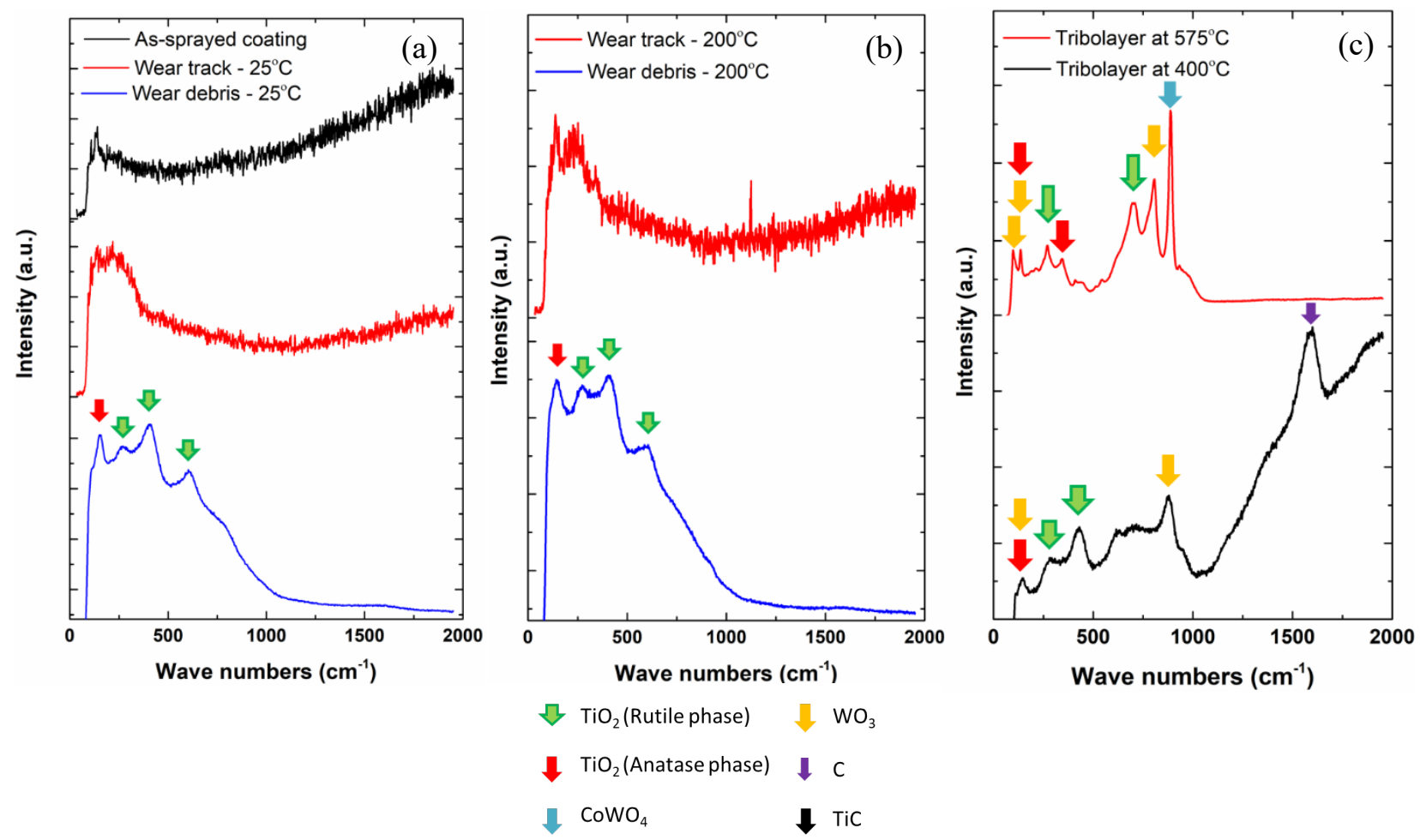

Fig. 5: Raman spectra of Ti6Al4V coatings corresponding to (a) as-sprayed coating, wear track and wear debris at $25^{\circ} \mathrm{C} \mathrm{(b)} \mathrm{wear} \mathrm{track} \mathrm{and} \mathrm{wear} \mathrm{debris} \mathrm{at} 200^{\circ} \mathrm{C}$ (c) tribolayer at $400^{\circ} \mathrm{C}$ and $575^{\circ} \mathrm{C}$

Raman analysis on the tribolayer and wear track of composite coatings revealed distinct phases with an increase in test temperatures. At $25^{\circ} \mathrm{C}$ and $200^{\circ} \mathrm{C}$, tribolayers on the track showed peaks corresponding to $\mathrm{TiO}_{2}$ along with $\mathrm{TiC}$ (Fig. 6b). However, the carbon peaks corresponding to a Raman shift of $1335 \mathrm{~cm}^{-1}$ (D-band) and $1583 \mathrm{~cm}^{-1}$ (G-band) were significantly broad and different compared to the peaks observed in the initial TiC particle (see Fig. 6a). Wear debris on the side of the $25^{\circ} \mathrm{C}$ wear tracks showed the presence of $\mathrm{TiC}$ and $\mathrm{TiO}_{2}$ phases indicating that the debris were predominantly the oxide particles of $\mathrm{Ti}$ and exposed $\mathrm{TiC}$ particles (Fig. 6b). At $400^{\circ} \mathrm{C}$, the wear debris showed peaks corresponding to $\mathrm{TiO}_{2}$ whereas the tribolayer showed additional peaks of $\mathrm{WO}_{3}$ along with $\mathrm{TiC}$ (Fig. 6c). The tribolayer covering the wear track at $575^{\circ} \mathrm{C}$ showed an additional high-intensity sharp peak of $\mathrm{CoWO}_{4}$ along with $\mathrm{TiO}_{2}, \mathrm{TiC}_{\text {and }} \mathrm{WO}_{3}$ peaks (Fig. 6c). 

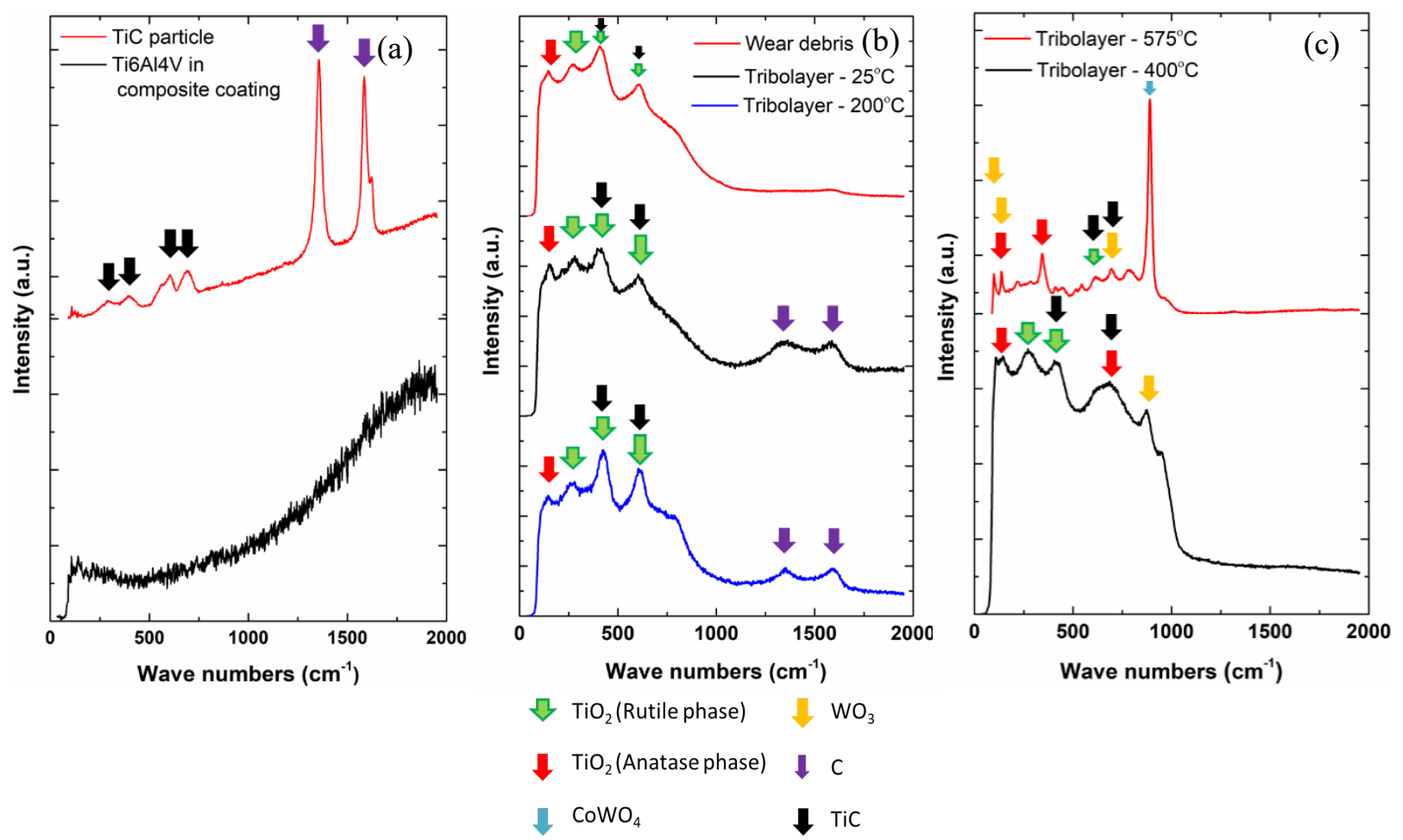

Fig. 6: Raman spectra of (a) as-sprayed composite coating (TiC particle and Ti6Al4V matrix); worn composite coatings corresponding to (b) tribolayers at $25^{\circ} \mathrm{C}, 200^{\circ} \mathrm{C}$ and wear debris (c) tribolayer at $400^{\circ} \mathrm{C}$ and $575^{\circ} \mathrm{C}$

\subsubsection{Counterface analysis}

The WC-Co counterfaces after the sliding test were examined under SEM and optical profilometer to characterize the worn morphology and to determine the wear volume. At $25^{\circ} \mathrm{C}$ and $200^{\circ} \mathrm{C}$, there was no observable ball wear. However, at $400^{\circ} \mathrm{C}$ and $575^{\circ} \mathrm{C}$, there was ball wear for counterfaces used in wear tests on both coatings. The volume of material worn from the ball after the sliding wear tests at different temperatures are summarized in Table 2. For tests on both coatings, the wear volume of the counterface was higher at $400^{\circ} \mathrm{C}$ compared to $575^{\circ} \mathrm{C}$.

Counterfaces sliding on the Ti6Al4V coatings for tests at $25^{\circ} \mathrm{C}$ (Fig. 7a) and $200^{\circ} \mathrm{C}$ (not shown here) showed the coverage of the contact surface with the wear debris and transfer layer. Raman analysis on the wear debris showed characteristic peaks corresponding to $\mathrm{TiO}_{2}$ (Fig. 7d) whereas on the transfer layer, no active Raman peak was found indicating the transfer of Ti6Al4V on to the ball. As the test temperature was increased to $400^{\circ} \mathrm{C}$, wear scar was found on the counterface with wear debris at its circumference as seen in Fig. 7b. Raman analysis on the wear debris revealed 
peaks corresponding to $\mathrm{TiO}_{2}$ along with $\mathrm{WO}_{3}$ as shown in Fig. 7e, similar to the phases found on the tribolayer of the wear track. At $575^{\circ} \mathrm{C}$, minimal wear was observed on the ball (Fig. 7c) corresponding to the low ball wear volume reported in Table 2. Furthermore, scattered wear debris were found at the contact interface, with few at the point of contact, which could have occurred during the wear process. Raman peaks corresponding to $\mathrm{CoWO}_{4}, \mathrm{WO}_{3}$ and $\mathrm{TiO}_{2}$ were observed on the wear debris as shown in Fig. $7 f$.

Table 2: Wear volume of the counterface

\begin{tabular}{ccc}
\hline Coating & Temperature $\left({ }^{\circ} \mathbf{C}\right)$ & Wear volume $\left(\boldsymbol{\mu m}^{\mathbf{3}}\right) \mathbf{x} \mathbf{1 0}^{\mathbf{4}}$ \\
\hline Ti6Al4V and Ti6Al4V-TiC & $25^{\circ} \mathrm{C}$ and $200^{\circ} \mathrm{C}$ & No wear \\
Ti6A14V & $400^{\circ} \mathrm{C}$ & $92 \pm 6$ \\
Ti6Al4V-TiC & $400^{\circ} \mathrm{C}$ & $120 \pm 13$ \\
Ti6A14V & $575^{\circ} \mathrm{C}$ & $0.3 \pm 0.1$ \\
Ti6A14V-TiC & $575^{\circ} \mathrm{C}$ & $1.2 \pm 0.5$ \\
\hline
\end{tabular}
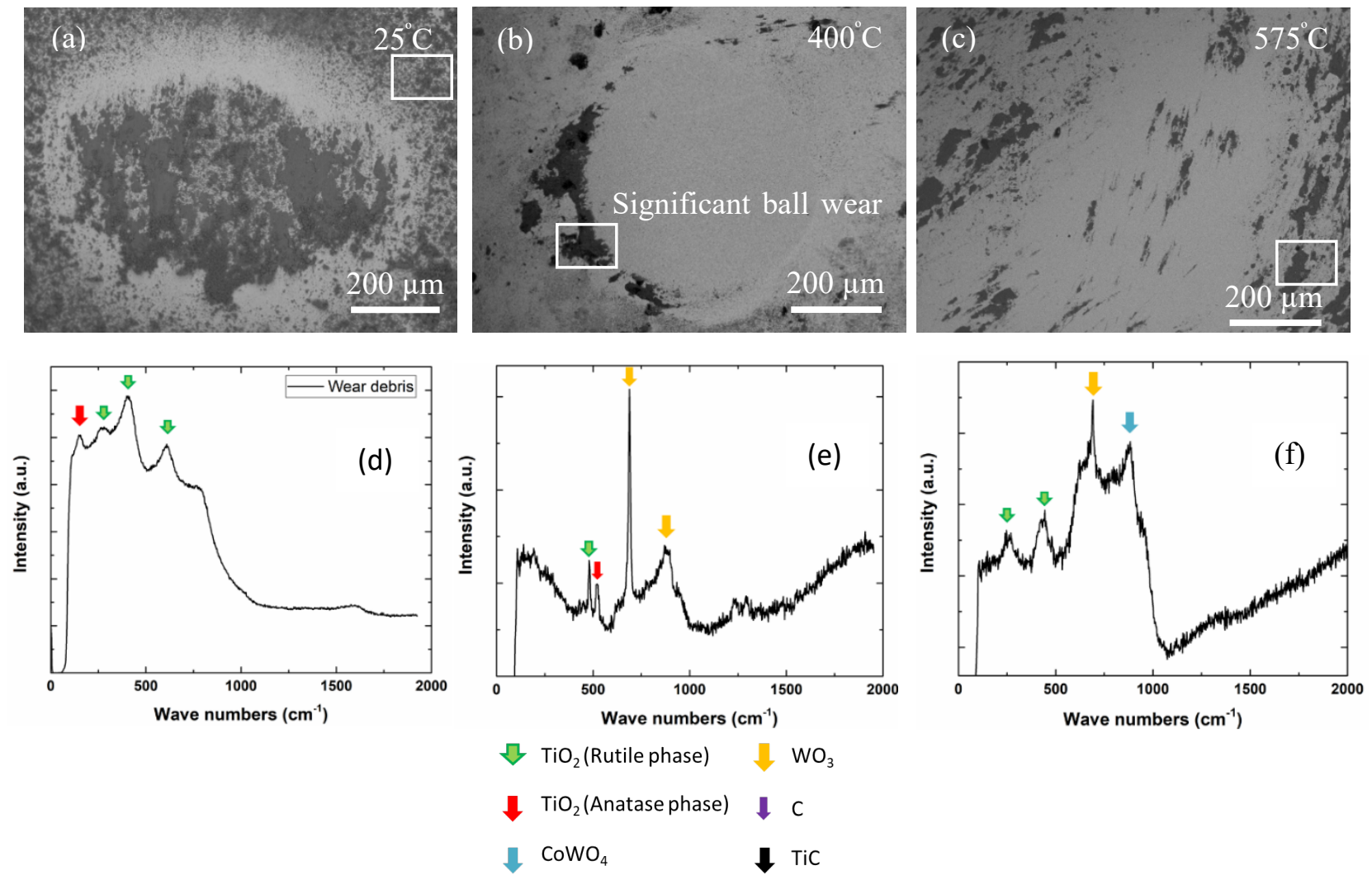

Fig. 7: SEM images of the counterfaces used on Ti6Al4V coatings at (a) $25^{\circ} \mathrm{C}$ (b) $400^{\circ} \mathrm{C}$ (c) $575^{\circ} \mathrm{C}$; (d), (e) and (f) Raman spectra at corresponding places shown with a box. 
Figure 8 shows the SEM images of the counterfaces used for sliding tests on composite coatings at different temperatures. At $25^{\circ} \mathrm{C}$ (see Fig. 8a) and $200^{\circ} \mathrm{C}$ (not shown here), formation of transfer film and wear debris at the contact surface was found on the counterface. Raman analysis on the transfer film formed at the contact interface showed characteristic peaks corresponding to $\mathrm{TiO}_{2}$ and $\mathrm{TiC}$ (see Fig. 8d) whereas scans on the wear debris showed peaks corresponding to $\mathrm{TiO}_{2}$. As the temperature increased to $400^{\circ} \mathrm{C}$, the wear scar (see Fig. 8b) showed significant wear of the counterface surrounded by wear debris. Raman analysis on the wear debris revealed characteristic peaks corresponding to $\mathrm{TiO}_{2}, \mathrm{TiC}$ and $\mathrm{WO}_{3}$ (Fig. 8e). At $575^{\circ} \mathrm{C}$, the ball wear significantly reduced compared to that of $400^{\circ} \mathrm{C}$ where no visible wear scar was found in the SEM image. Additionally, wear debris were found to be aligned in the sliding direction as seen in Fig. 8c. Raman peaks on the debris showed an additional phase of $\mathrm{CoWO}_{4}$ along with $\mathrm{TiO}_{2}, \mathrm{TiC}$ and $\mathrm{WO}_{3}$ (Fig. 8f) similar to Ti6Al4V coatings at $575^{\circ} \mathrm{C}$. However, the volume fraction of wear debris found were low compared to previous temperatures indicating less transfer of material from the coating.
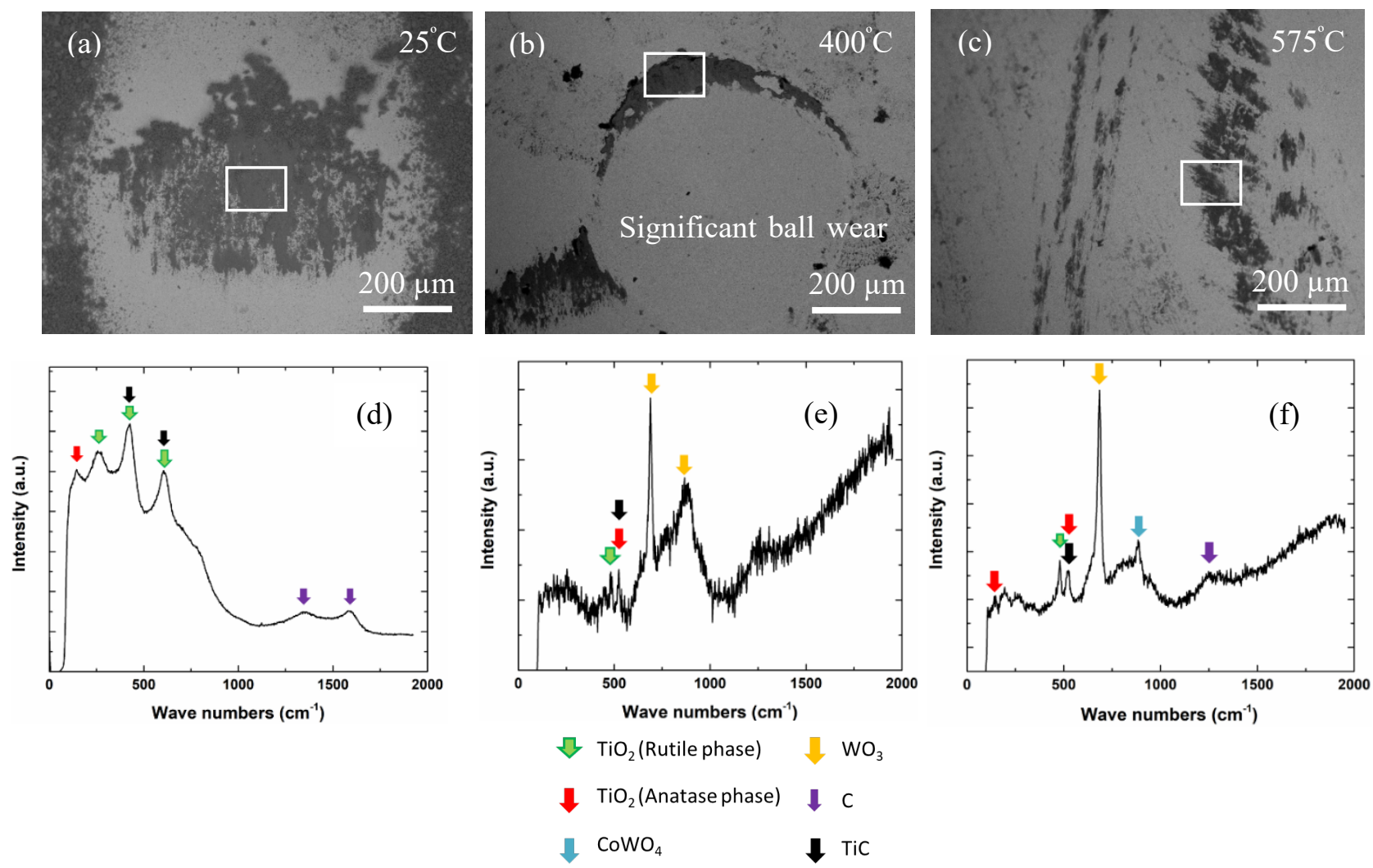

Fig. 8: SEM images of the counterfaces used on composite coatings at (a) $25^{\circ} \mathrm{C}$ (b) $400^{\circ} \mathrm{C}$ (c) $575^{\circ} \mathrm{C}$; (d), (e) and (f) Raman spectra at corresponding places shown with a box. 


\subsubsection{Subsurface analysis}

Figures 9 and 10 show the ECCI of the cross-sectional wear track subsurface of the Ti6Al4V and composite coatings tested at different temperatures. For the Ti6Al4V coatings at $25^{\circ} \mathrm{C}$, there were no observable tribolayers, while underneath the wear track, debonding of splats (see Fig. 9a) was seen up to $\sim 600 \mu \mathrm{m}$ into the coating due to the transfer of stress to the subsurface during wear. The initial static maximum Hertzian contact stress in the case of Ti6Al4V was $\sim 0.8 \mathrm{GPa}$ and the maximum stress point was $\sim 19 \mu \mathrm{m}$ below the contact surface. At $200^{\circ} \mathrm{C}$, discontinuous tribolayers were observed due to compaction of wear debris. Below the tribolayers, ultrafine-grained region up to a depth of $\sim 2.5 \mu \mathrm{m}$ and recrystallized regions were seen (Fig. 9b and 9c). As the temperature was increased to $400^{\circ} \mathrm{C}$ and $575^{\circ} \mathrm{C}$, a more continuous tribolayer was found on wear track (Fig. 9d and 9g). Tribolayer was of $\sim 10 \pm 1.8 \mu \mathrm{m}$ at $400^{\circ} \mathrm{C}$ and $\sim 3.5 \pm 0.5 \mu \mathrm{m}$ at $575^{\circ} \mathrm{C}$ with cracks inside them (see Fig. $9 \mathrm{~d}$ and $9 \mathrm{~g}$ ). At $400^{\circ} \mathrm{C}$, underneath the tribolayer ultrafine-grained region of $\sim 1.5$ $\mu \mathrm{m}$ thickness was observed followed by a recrystallized region (Fig. 9f). In contrast, at $575^{\circ} \mathrm{C}$ below the tribolayer ultrafine grains were not seen, however, microcrystalline grains of grain size $\sim 0.8 \mu \mathrm{m}$ (see Fig. $9 \mathrm{~h}$ ), similar to the grain size in the thermally cycled region (i.e. region away from the wear track) were observed. Additionally, de-bonding of the splats were observed at all test temperatures below the wear track and tribolayers, however the extent of debonding decreased as the temperature increased (Fig. 9).

In the case of the composite coatings, tribolayers were observed at all test temperatures due to the presence of stabilizing TiC particles. At $25^{\circ} \mathrm{C}$, tribolayer of $\sim 8.2 \pm 2.7 \mu \mathrm{m}$ was found on the wear track with no evidence of splat debonding beneath the tribolayers. Composite coatings at $200^{\circ} \mathrm{C}$ showed discontinuous tribolayers of thickness $\sim 7.5 \pm 2.7 \mu \mathrm{m}$ as seen in Fig. 10c, that coincides with the SEM image of the wear track morphology. This was followed by ultrafine grains up to a depth of $\sim 2 \mu \mathrm{m}$ and subsequently by recrystallized region (Fig. 10d). At $400^{\circ} \mathrm{C}$, a tribolayer of thickness $\sim 2.5 \pm 0.4 \mu \mathrm{m}$ (Fig. 10e) was observed and below it similar to Ti6A14V coatings, ultrafine-grained region was found up to a thickness of $\sim 2 \mu \mathrm{m}$ with few fragments of carbide particles, followed by recrystallized grains that extended into the coating (see Fig. 10f). At a test temperature of $575^{\circ} \mathrm{C}$, a thin tribolayer (Fig. $10 \mathrm{~g}$ ) was observed with recrystallized grains of size $\sim 1.5 \mu \mathrm{m}$ underneath as seen in Fig. $10 \mathrm{~h}$. 

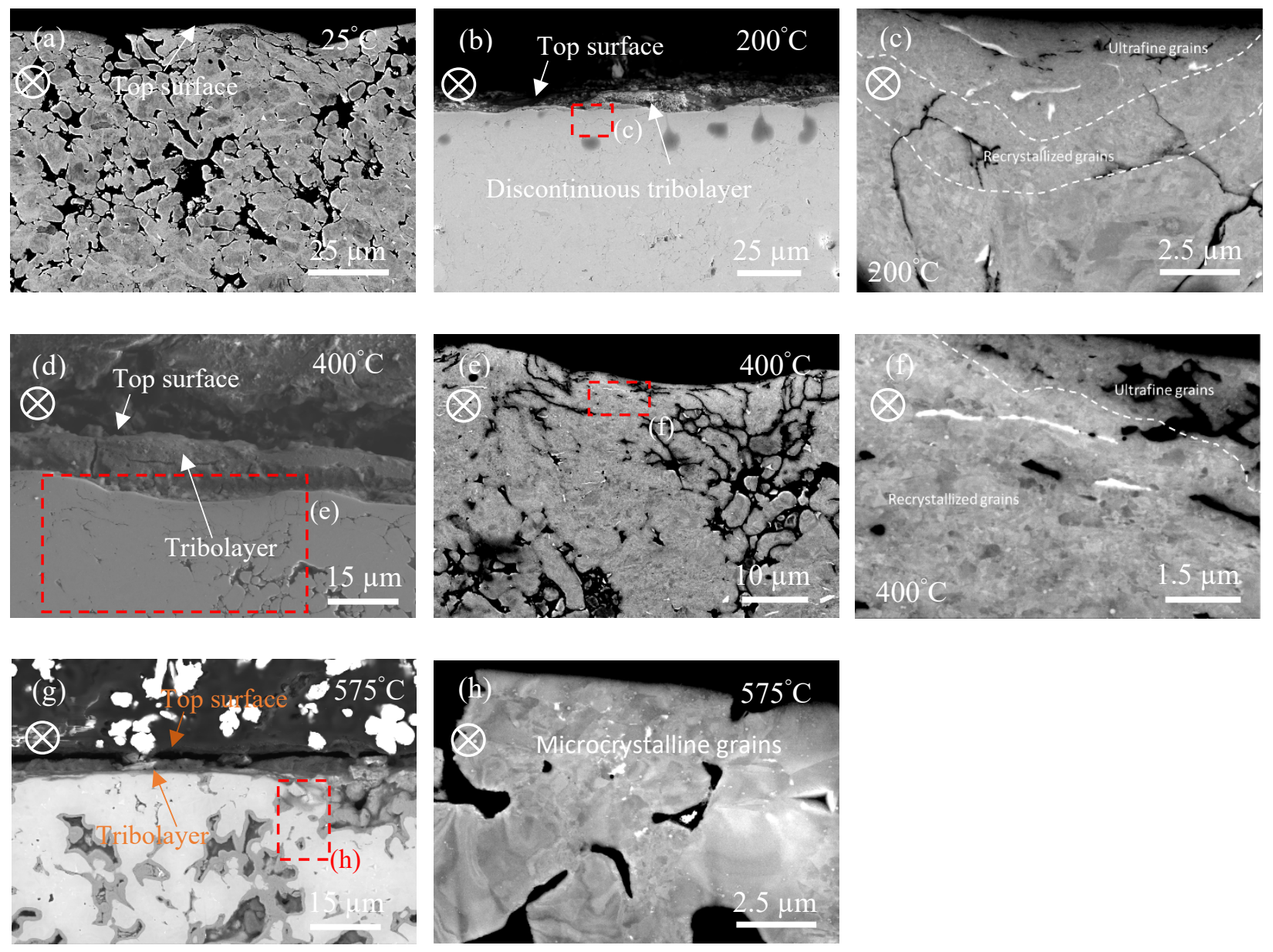

Fig. 9: SEM images of tribolayers of Ti6Al4V coatings at (a) $25^{\circ} \mathrm{C}$ (b) $200^{\circ} \mathrm{C}$ (d) $400^{\circ} \mathrm{C}$ (g) $575^{\circ} \mathrm{C}$ and (c), (e), (f) and (h) ECCI of the subsurface respectively. The red box in the SEM images shows the sub-surface region where the ECCI was done. $\bigotimes$ - indicates sliding direction 

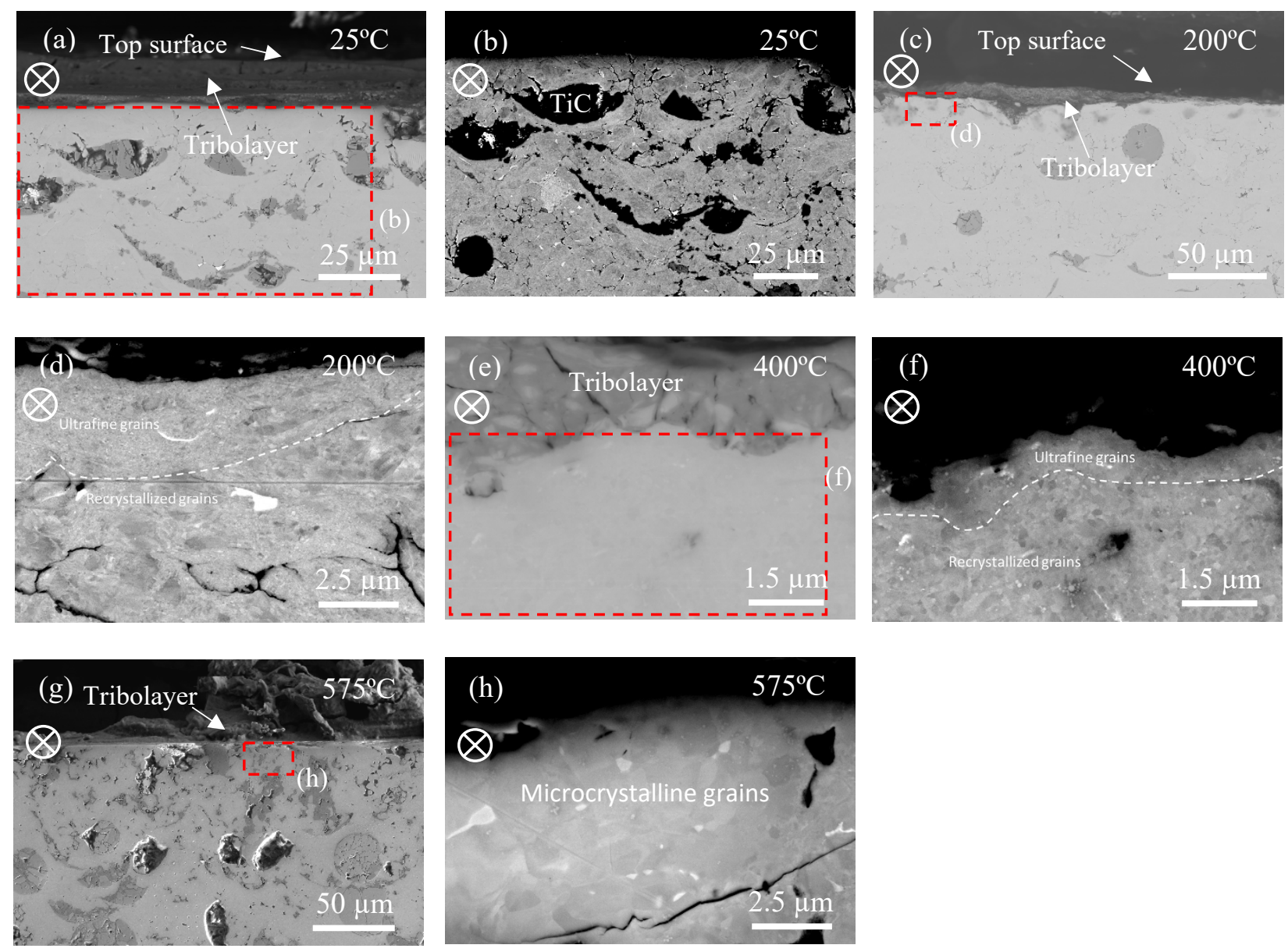

Fig. 10: SEM images of tribolayers of composite coatings at (a) $25^{\circ} \mathrm{C}$ (c) $200^{\circ} \mathrm{C}$ (e) $400^{\circ} \mathrm{C}(\mathrm{g}) 575^{\circ} \mathrm{C}$ and (b), (d) and (f) ECCI of the subsurface respectively. The red box in the SEM images shows the sub-surface region where the ECCI was done. $\boldsymbol{\bigotimes}$ - indicates sliding direction

Hardness of the tribolayers and the unworn coating at different test temperatures is shown in Fig. 11. Tribolayers were formed on the wear tracks of Ti6Al4V-TiC composite coatings at all test temperatures and in Ti6Al4V coatings at elevated temperatures $\left(>200^{\circ} \mathrm{C}\right)$. Below $200^{\circ} \mathrm{C}$, no stable and continuous tribolayers were formed on the wear tracks on the Ti6Al4V coatings, hence the hardness of the subsurface underneath the wear track (i.e. ultra fine grain region) was plotted in Fig. 11. The hardness of the tribolayers for both coatings was higher than the unworn surfaces at all test temperatures. At the lower two test temperatures $\left(25\right.$ and $\left.200^{\circ} \mathrm{C}\right)$, the tribolayer hardness was similar, with the tribolayers on the composite coating being harder than for Ti6Al4V coatings. This was also true for $400^{\circ} \mathrm{C}$ and at all three of the lower test temperatures there was sufficient coating wear that fragmented $\mathrm{TiC}$ particles were likely incorporated into the tribofilms, leading to higher hardness. Also of note, at $400^{\circ} \mathrm{C}$ and $575^{\circ} \mathrm{C}$ the hardness of tribofilms for both coatings (see 
Fig. 11) become harder than at lower temperatures. In both cases, this is due to oxidation and glaze layer formation. At $575^{\circ} \mathrm{C}$, the tribolayers of both Ti6Al4V and composite coatings showed similar hardness, which was the highest measured, and was connected to oxide glaze layer formation with minimal wear of the coatings.

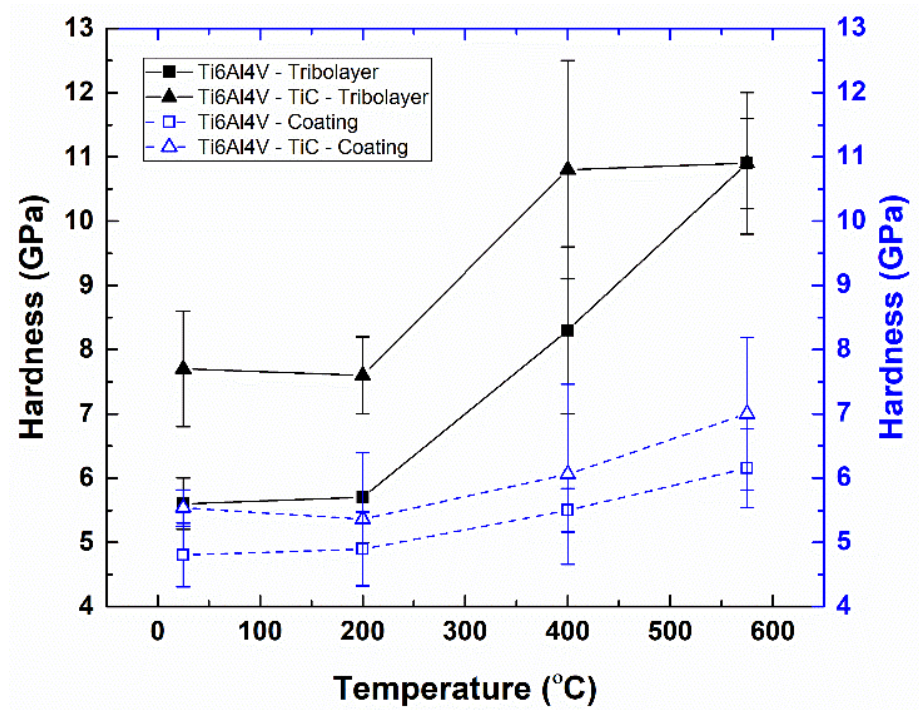

Fig. 11: Hardness of the tribolayer and coating at different static test temperatures

\section{Discussion}

MMCs, used as bulk materials or coatings, are designed to resist mechanical stresses better than the pure metal or alloy used as the matrix. From a tribological standpoint, the hard particles provide load support to resist the hydrostatic and shearing stresses at the interface of a sliding contact. However, recent research has also shown that the hard particles modify local stress states or accelerate the formation of wear-resistant tribofilms $[5,9,21,22]$. These tribofilms are often formed by oxidative wear of the matrix material but can also incorporate some of the hard particles. The chemical and mechanical mixing that forms these tribofilms may be modified by changes in ambient temperature. In this study of Ti6Al4V and Ti6Al4V-TiC coatings, the hard particles were effective in the manner described above and changes in the tribofilm composition with temperature were linked to changes in the wear mechanisms and wear rates. As will be discussed below, the wear mechanisms and the properties of third bodies were changed by temperature, with the $\mathrm{TiC}$ in the composite coating making the processes distinctly different from the pure Ti6Al4V coating. 
A schematic of the wear mechanisms occurring in Ti6Al4V and Ti6Al4V-TiC composite coatings at lower $\left(<200^{\circ} \mathrm{C}\right)$ and higher $\left(>200^{\circ} \mathrm{C}\right)$ test temperatures is shown in Fig. 12. Up to $200^{\circ} \mathrm{C}$, Ti6Al4V coatings showed high wear rates compared to composite coatings due to abrasive wear caused by the trapped wear debris at the interface (see Fig. 3a and 3c). The wear debris were composed of oxides of Ti that acted like abrasive particles during sliding wear, resulting in material ploughing until getting displaced to either side of the wear track (Fig. 12a and Fig. 3a). Additionally, the formation of an adhesive transfer film of Ti6Al4V on the counterface was observed at both the test temperatures (Fig. 7a), due to the low d-bond character of Ti and its alloys $[9,23]$. Along with the transfer film, wear debris were found around the transfer film (on the counterface). At $25^{\circ} \mathrm{C}$, no tribolayers were formed, whereas at $200^{\circ} \mathrm{C}$, minor evidence of tribolayer formation due to compaction of wear debris was observed on the wear track. However, the tribolayers were non-protective and their poor resistance to the localized deformation induced by the counterface during sliding led to the transfer of stress to the subsurface [9]. This resulted in debonding of particle-particle interfaces underneath the wear track (see Fig. 9a). Similar evidence of loose, non-adherent and non-protective tribolayer formation, which led to high wear of $\mathrm{Ti}$ and its alloys up to $200^{\circ} \mathrm{C}$ was reported by Straffelini et al., Cui et al., Molinari et al., Chen et al. and Mao et al. $[13,15,24-26]$ Furthermore, the high affinity of Ti and its alloys towards oxygen results in the early formation of oxides. However, its high "Pilling-Bedworth ratio" results in internal stresses in the oxide layers (that are further enhanced during the wear process) and the mismatch for the coefficient of thermal expansion between the oxide layer and subsurface material result in their breakage $[13,25,27]$. These fragmented oxide debris further act as abrasive particles and accelerate the wear process resulting in high wear rates.

Reinforcement of $\mathrm{TiC}$ ceramic particles into Ti6A14V matrix improved the wear resistance. This was due to the formation of tribolayers on the wear track (Fig. 12b) and could also be due to the improvement in the hardness of the coating making it resistant to plastic deformation. Previously, Alidokht et al. reported the formation of tribolayers around TiC particles in Ti-TiC MMC coatings and illustrated that their reinforcement in the metallic matrix offered resistance to plastic deformation during sliding [9]. Candel et al. also found that the presence of TiC particles in Ti6A14V matrix resulted in the formation of tribolayers that decreased the friction and wear of the MMC coatings [28]. Similar tribolayers composed of fragmented oxide debris of $\mathrm{Ti}$ and $\mathrm{TiC}$ particles were found on the wear track of composite coatings at both $25^{\circ} \mathrm{C}$ and $200^{\circ} \mathrm{C}$ (see Fig. 4a). 
Formation of tribolayers on the wear track offered resistance to localized plastic shearing and thus improved the wear resistance of the coatings. Studies performed by Venkataraman et al. illustrated that the presence of hard tribolayer resulted in mild wear with lower wear rates in Al based composites compared to the pure Al where there was no evidence of tribolayer [3]. Similar improvements in wear resistance due to the formation of tribolayers were reported by Torgerson et al., Shockley et al., Alidokht et al., Zhang et al. and Cui et al. [6,8,11,13,29] Thus, reinforcing TiC ceramic particles in the Ti6Al4V matrix facilitated the formation of the protective tribolayers and their presence in the form of fragments in the tribolayers (Fig. 12b) offered resistance to localized plastic deformation during sliding wear, leading to improved wear resistance [9,28].

Beyond $200^{\circ} \mathrm{C}$, oxide glaze layers formed on the wear tracks of both coatings were composed of $\mathrm{TiO}_{2}, \mathrm{WO}_{3}$ and $\mathrm{CoWO}_{4}$ (only at $575^{\circ} \mathrm{C}$ ) and significantly improved the wear resistance compared to lower temperatures. At elevated temperatures $\left(>200^{\circ} \mathrm{C}\right)$, a similar mechanism for the formation of tribolayers in Ti and its alloys were reported by Cui et al., Wang et al. and Chen et al. [13-15] Furthermore, composite coating showed almost no wear in addition to material gain on the wear track by material transfer from the counterface, which resulted in negative wear rates. Additionally, the glaze layers of composite coatings showed relatively uniform coverage compared to Ti6Al4V coatings. The formation of $\mathrm{WO}_{3}$ and $\mathrm{CoWO}_{4}\left(\right.$ only at $575^{\circ} \mathrm{C}$ ) phases in the glaze layers was due to the oxidation and wear of the WC-Co counterface, resulting in the transfer of material onto the wear track (see Fig. 7 and 8). Prior studies have shown that WC-Co composites exhibit high wear resistance up to $200^{\circ} \mathrm{C}$, while beyond this temperature, oxidation results in significant wear along with the formation of oxides of $\mathrm{W}$ and Co [19,20,30]. This was consistent with the observations made in this study, where ball wear occurred only beyond $200^{\circ} \mathrm{C}$ and hence no oxides of $\mathrm{W}$ and Co were detected on the wear tracks at $25^{\circ} \mathrm{C}$ and $200^{\circ} \mathrm{C}$ (Fig. 5 and 6).

The tribolayer hardness of composite coatings was found to be higher compared to Ti6Al4V due to the presence of fragmented $\mathrm{TiC}$ particles; however, at $575^{\circ} \mathrm{C}$, tribo-oxidation lead to limited pulling out and subsequent fragmentation resulting in similar hardness. Ultrafine recrystallized grains were found beneath the glaze layers in both coatings up to $400^{\circ} \mathrm{C}$. The formation of ultrafine region was due to dynamic recrystallization that occurs due to stress transfer during the wear process. In contrast, at $575^{\circ} \mathrm{C}$, micron sized grains were observed underneath the glaze layers that were similar to the thermally cycled region (i.e. region away from the wear track) indicating 
recrystallization had occurred prior to the start of wear tests at this temperature. However, the average grain size beneath the glaze layer was higher in the composite coatings compared to Ti6Al4V indicating these coatings were more resistant to subsurface deformation.

The average CoF in Ti6Al4V and Ti6Al4V-TiC coatings decreased with an increase in temperature. Below $200^{\circ} \mathrm{C}$, the average $\mathrm{CoF}$ of Ti6Al4V and composite coatings did not vary significantly with temperature. However, as the test temperature was increased to $400^{\circ} \mathrm{C}$ and $575^{\circ} \mathrm{C}$, the formation of new phases changed the tribo-chemistry resulting in a decrease in $\mathrm{CoF}$. Erdemir et al. proposed that higher ionic potential of the oxides result in greater screening of the cations by the anions and prevent their additional reactivity with the other available atoms which reduces the adhesion and thereby the $\mathrm{CoF}[31,32]$. At $400^{\circ} \mathrm{C}, \mathrm{WO}_{3}$ was detected on the wear track of both coatings, which has a high ionic potential of $\sim 8.3$ and exhibits CoF within a range of 0.25 - 0.33 [32]. However, the decrease in $\mathrm{CoF}$ was more significant in the case of composite coatings due to a higher amount of $\mathrm{W}$ transferred from the counterface with more uniform coverage over the entire wear track (Fig. 4d). Additionally, abrasive grooves were observed on the wear track of Ti6Al4V coatings even at $400^{\circ} \mathrm{C}$ which could have led to a higher CoF despite the presence of $\mathrm{WO}_{3}$ (see Fig. 3c). Similar trends of a decrease in $\mathrm{CoF}$ due to the presence of $\mathrm{WO}_{3}$ on the wear track was reported by Geng et al. and Mi et al. [19,20,30]. With a further increase in test temperature to $575^{\circ} \mathrm{C}, \mathrm{CoWO}_{4}$ was additionally found on the wear track along with $\mathrm{TiO}_{2}$ and $\mathrm{WO}_{3}$. Previously, Erdemir et al. illustrated that the large differences in the ionic potentials of the chemical species result in lower $\mathrm{CoF}$ [32]. Their observations revealed that $\mathrm{CoWO}_{4}$ (that exists as $\mathrm{CoO}-\mathrm{WO}_{3}$ ) had an ionic potential difference of 6.9 and exhibited $\mathrm{CoF}$ in the range of $0.2-0.47$ at temperatures between $573 \mathrm{~K}-1072 \mathrm{~K}$. This coincides with the low CoF values observed in our study where the formation of $\mathrm{CoWO}_{4}$ significantly decreased the $\mathrm{CoF}$ in both coatings at $575^{\circ} \mathrm{C}$.

Thus, reinforcement of TiC ceramic particles favoured the formation of wear resistant tribolayers at lower temperatures unlike the pure Ti6Al4V coating, whereas, tribo-oxidation led to the formation of oxide glaze layers comprising of $\mathrm{WO}_{3}$ and $\mathrm{CoWO}_{4}$ at elevated temperatures that reduced the $\mathrm{CoF}$ and wear for both coatings. 
(a)
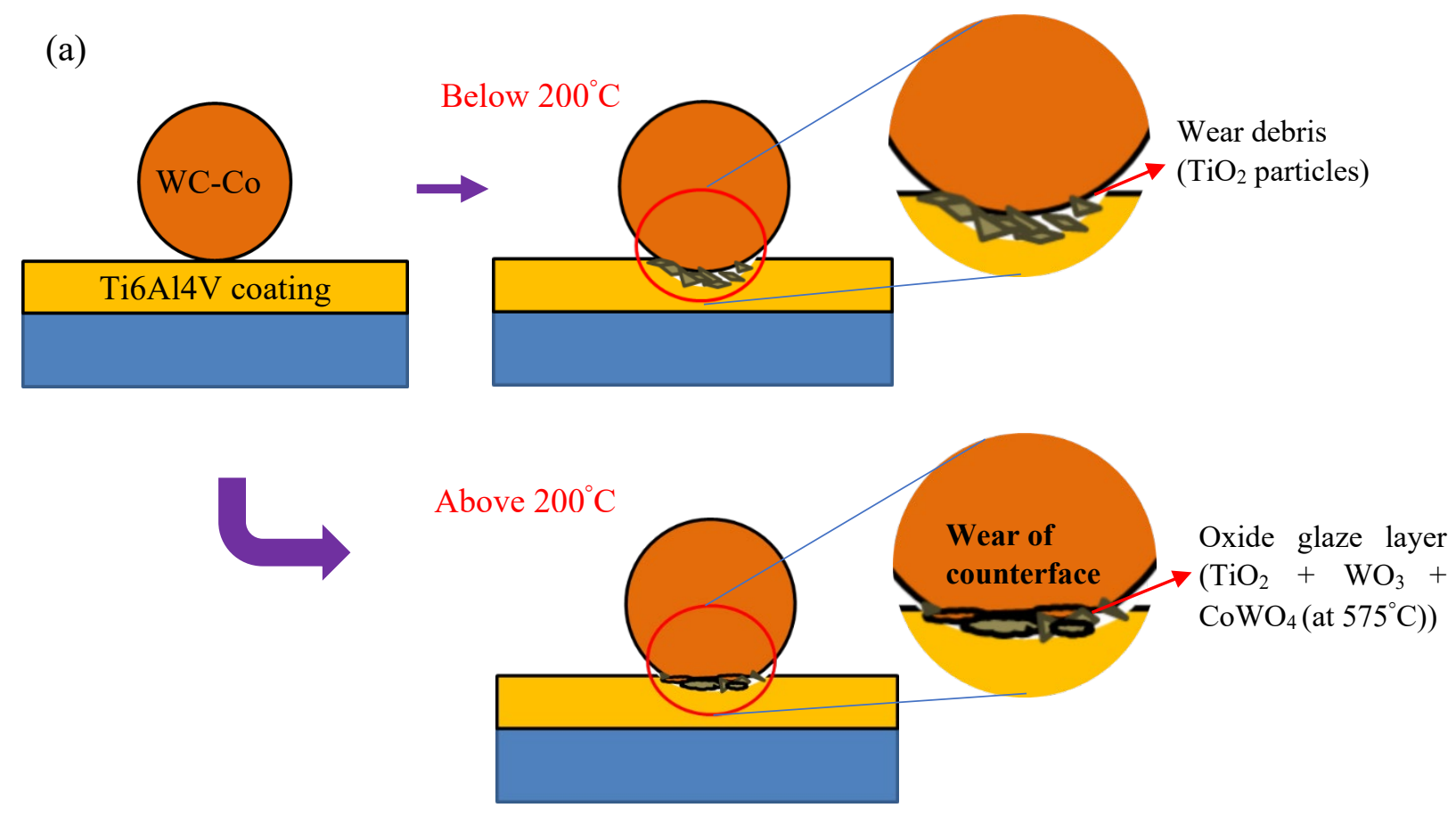

(b)
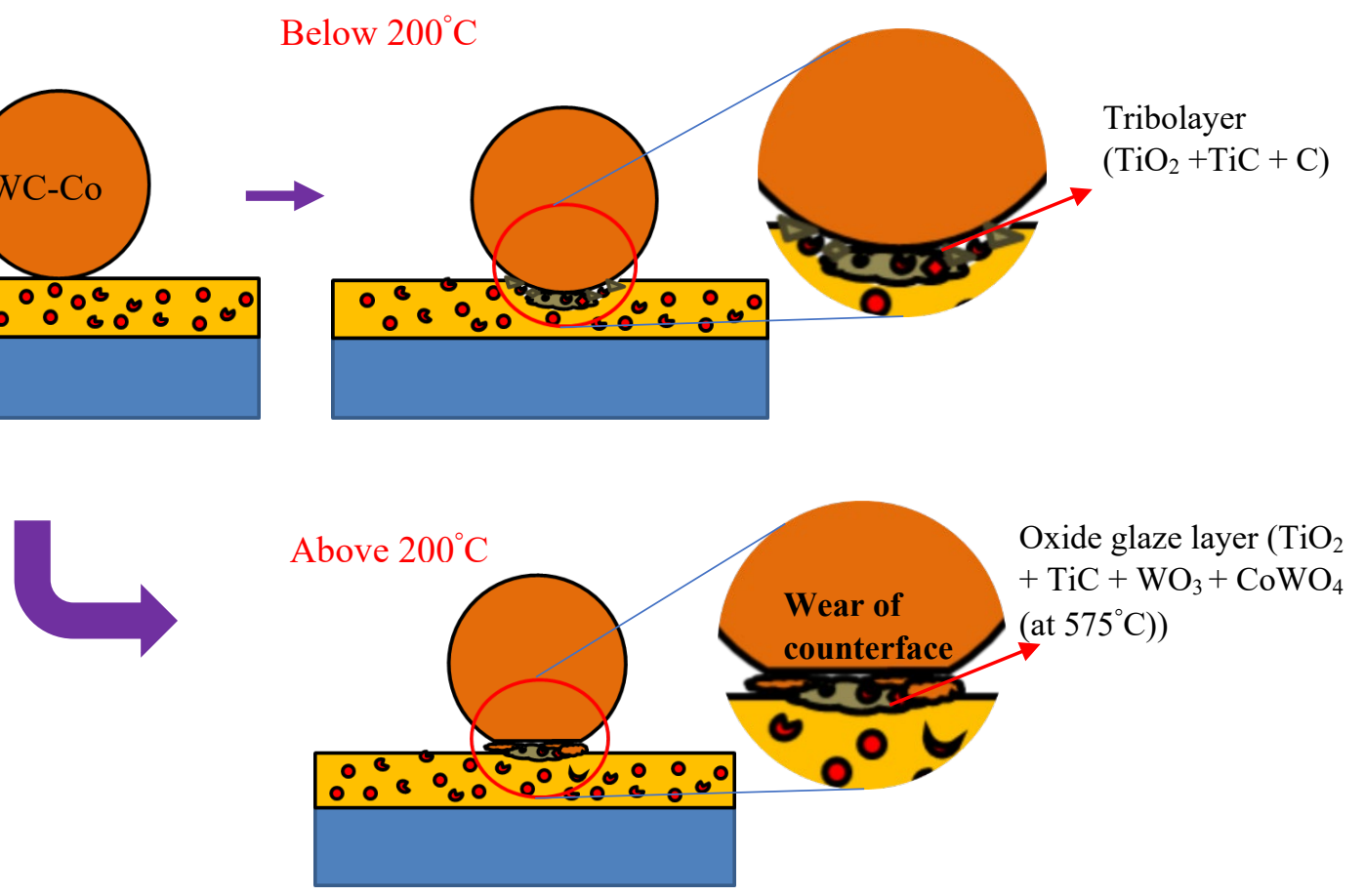

Fig. 12: Schematic showing the third bodies chemical compositions and wear mechanisms in (a) Ti6Al4V and (b) Ti6Al4V-TiC MMC coatings at different static test temperatures 


\section{Conclusions}

Ti6Al4V and Ti6Al4V-TiC MMC coatings were deposited using CS process and their high temperature sliding friction, wear behavior, tribochemical phase formation and wear mechanisms were studied in detail. Based on the results following conclusions were drawn:

1. At lower test temperatures, abrasive grooves along the sliding direction were observed in Ti6A14V coatings whereas tribolayers were found on the wear track of composite coatings. This indicated that the reinforced $\mathrm{TiC}$ ceramic particles favoured the formation of tribolayers that resist localized deformation and result in low wear of composite coatings compared to Ti6Al4V.

2. The wear rate of Ti6Al4V and Ti6Al4V-TiC composite coatings was lower at elevated temperatures. This was due to a transition in wear mechanisms to tribo-oxidation that led to oxide glaze layers composed of $\mathrm{TiO}_{2}, \mathrm{WO}_{3}$ and $\mathrm{CoWO}_{4}$ phases on the wear track. Glaze layers were partially formed by wear and oxidation of the WC-Co counterface followed by adhesive transfer to the wear track. Even with this material transfer, the Ti6Al4V coatings showed a measurable positive wear rate. The composite coating, with reinforced TiC, showed a negative wear rate, indicating minimal true wear of the coating and mostly glaze layer formation.

3. Interparticle de-bonding was seen underneath the tribolayers of Ti6Al4V coatings due to the transfer of stress to the subsurface, while the formation of tribolayers comprising of oxides of $\mathrm{Ti}$ and $\mathrm{TiC}$ particles increased their load bearing capacity and prevented debonding in composite coatings.

4. Average $\mathrm{CoF}$ decreased with increasing temperature in both coatings. Below $200^{\circ} \mathrm{C}$, the CoF of Ti6Al4V and Ti6Al4V-TiC composite coatings did not vary significantly with temperature. However, at elevated temperatures, formation of glaze layers composed of oxides of $\mathrm{W}$ and Co reduced the adhesion and decreased the CoF. 


\section{Acknowledgements}

The authors are thankful for the technical assistance from Phuong Vo, Maniya Aghasibeig and Jean-Francois Alarie at McGill Aerospace Materials and Alloy Design Centre (MAMADC). The authors gratefully acknowledge the contributions of Rene Cooper from Cristal Metals for providing the irregular Ti6Al4V powders.

\section{References}

[1] W. Li, H. Assadi, F. Gaertner, S. Yin, A review of advanced composite and nanostructured coatings by solid-state cold spraying process, Crit. Rev. Solid State Mater. Sci. 8436 (2018) $1-48$.

[2] J.M. Shockley, H.W. Strauss, R.R. Chromik, N. Brodusch, R. Gauvin, E. Irissou, J.G. Legoux, In situ tribometry of cold-sprayed Al-A12O3 composite coatings, Surf. Coatings Technol. 215 (2013) 350-356.

[3] B. Venkataraman, G. Sundararajan, Correlation between the characteristics of the mechanically mixed layer and wear behaviour of aluminium, Al-7075 alloy and Al-MMCs, Wear. 245 (2000) 22-38.

[4] J.M. Shockley, S. Descartes, E. Irissou, J.G. Legoux, R.R. Chromik, Third body behavior during dry sliding of cold-sprayed Al-Al2O3composites: In situ tribometry and microanalysis, Tribol. Lett. 54 (2014) 191-206.

[5] R.R. Chromik, S.A. Alidokht, J.M. Shockley, Y. Zhang, Tribological coatings prepared by cold spray, in: Cold-Spray Coatings, 2018: pp. 321-348.

[6] T.B. Torgerson, M.D. Harris, S.A. Alidokht, T.W. Scharf, S.M. Aouadi, R.R. Chromik, J.S. Zabinski, A.A. Voevodin, Room and elevated temperature sliding wear behavior of cold sprayed Ni-WC composite coatings, Surf. Coatings Technol. 350 (2018) 136-145.

[7] G. Maurice, The third-body approach: A mechanical view of wear, Wear. 100 (1984) 437452.

[8] S.A. Alidokht, P. Manimunda, P. Vo, S. Yue, R.R. Chromik, Cold spray deposition of a NiWC composite coating and its dry sliding wear behavior, Surf. Coatings Technol. 308 (2016) 424-434.

[9] S.A. Alidokht, V.N.V. Munagala, R.R. Chromik, Role of third bodies in friction and wear of cold-sprayed Ti and Ti-TiC composite coatings, Tribol. Lett. 65 (2017).

[10] A.T. Alpas, J. Zhang, Effect of microstructure and counterface material on the sliding wear resistance of particulate reinforced aluminum matrix composites, Met. Mater. Trans. A. 25 (1994) 969-983.

[11] Q.Y. Zhang, Y. Zhou, X.X. Li, L. Wang, X.H. Cui, S.Q. Wang, Accelerated formation of 
tribo-oxide layer and its effect on sliding wear of a titanium alloy, Tribol. Lett. 63 (2016).

[12] L. Du, C. Huang, W. Zhang, T. Li, W. Liu, Preparation and wear performance of $\mathrm{NiCr} / \mathrm{Cr} 3 \mathrm{C} 2-\mathrm{NiCr} / \mathrm{hBN}$ plasma sprayed composite coating, Surf. Coatings Technol. 205 (2011) 3722-3728.

[13] X.H. Cui, Y.S. Mao, M.X. Wei, S.Q. Wang, Wear Characteristics of Ti-6Al-4V Alloy at 20-400 ${ }^{\circ} \mathrm{C}$, Tribol. Trans. 55 (2012) $185-190$.

[14] L. Wang, Q.Y. Zhang, X.X. Li, X.H. Cui, S.Q. Wang, Severe-to-mild wear transition of titanium alloys as a function of temperature, Tribol. Lett. 53 (2014) 511-520.

[15] Q.Y. Zhang, X.H. Cui, L. Wang, X.X. Li, S.Q. Wang, K.M. Chen, Comparative study of wear behaviors of a selected titanium alloy and AISI H13 steel as a function of temperature and load, Tribol. Trans. 57 (2014) 838-845.

[16] V.N.V. Munagala, V. Akinyi, P. Vo, R.R. Chromik, Influence of powder morphology and microstructure on the cold spray and mechanical properties of Ti6Al4V coatings, J. Therm. Spray Technol. 27 (2018) 827-842.

[17] W.C. Oliver, G.M. Pharr, An improved technique for determining hardness and elastic modulus using load and displacement sensing indentation experiments, J. Mater. Res. 7 (1992) 1564-1583.

[18] M. Lubas, J.J. Jasinski, M. Sitarz, L. Kurpaska, P. Podsiad, J.J. Jasinski, Raman spectroscopy of TiO2 thin films formed by hybrid treatment for biomedical applications, Spectrochim. Acta - Part A Mol. Biomol. Spectrosc. 133 (2014) 867-871.

[19] Z. Geng, S. Li, D.L. Duan, Y. Liu, Wear behaviour of WC-Co HVOF coatings at different temperatures in air and argon, Wear. 330-331 (2015) 348-353.

[20] Z. Geng, S. Hou, G. Shi, D. Duan, S. Li, Tribological behaviour at various temperatures of WC-Co coatings prepared using different thermal spraying techniques, Tribol. Int. 104 (2016) 36-44.

[21] S.A. Alidokht, P. Vo, S. Yue, R.R. Chromik, Cold Spray deposition of Ni and WCreinforced Ni matrix composite coatings, J. Therm. Spray Technol. 26 (2017) 1908-1921.

[22] J. Michael Shockley, C. Desrayaud, R.R. Chromik, S. Descartes, Significance of Al2O3 particle morphology in the microstructure evolution of cold-sprayed Al-Al2O3 during unconstrained high-pressure torsion, Mater. Sci. Eng. A. 684 (2017) 510-516.

[23] H. Dong, T. Bell, Tribological behaviour of alumina sliding against Ti6Al4V in unlubricated contact, Wear. 225-229 (1999) 874-884.

[24] A. Molinari, G. Straffelini, B. Tesi, T. Bacci, Dry sliding wear mechanisms of the Ti6Al4V alloy, Wear. 208 (1997) 105-112.

[25] Y.S. Mao, L. Wang, K.M. Chen, S.Q. Wang, X.H. Cui, Tribo-layer and its role in dry sliding wear of Ti-6Al-4V alloy, Wear. 297 (2013) 1032-1039.

[26] G. Straffelini, A. Molinari, Dry sliding wear of Ti $-6 \mathrm{Al}-4 \mathrm{~V}$ alloy as influenced by the counterface and sliding conditions, Wear. 236 (1999) 328-338. 
[27] X.X. Li, Y. Zhou, X.L. Ji, Y.X. Li, S.Q. Wang, Effects of sliding velocity on tribo-oxides and wear behavior of Ti-6Al-4V alloy, Tribol. Int. 91 (2014) 228-234.

[28] J.J. Candel, V. Amigó, J.A. Ramos, D. Busquets, Sliding wear resistance of TiCp reinforced titanium composite coating produced by laser cladding, Surf. Coatings Technol. 204 (2010) 3161-3166.

[29] J.M. Shockley, S. Descartes, P. Vo, E. Irissou, R.R. Chromik, The influence of Al2O3 particle morphology on the coating formation and dry sliding wear behavior of cold sprayed Al-Al2O3 composites, Surf. Coatings Technol. 270 (2015) 324-333.

[30] P. Mi, T. Wang, F. Ye, Influences of the compositions and mechanical properties of HVOF sprayed bimodal WC-Co coating on its high temperature wear performance, Int. J. Refract. Met. Hard Mater. 69 (2017) 158-163.

[31] A. Erdemir, A crystal chemical approach to the formulation of self-lubricating nanocomposite coatings, Surf. Coatings Technol. 200 (2005) 1792-1796.

[32] A. Erdemir, A crystal-chemical approach to lubrication by solid oxides, Tribol. Lett. 8 (2000) 97-102. 